\title{
Kehebatan Situs Belanja Daring dalam Mempengaruhi Emosi dan Kepercayaan Pembeli
}

\author{
Ibnu Harris \\ Universitas Universal, Batam - Indonesia \\ Korespondensi: ibnu@uvers.ac.id
}

\begin{abstract}
Abstrak
Hampir semua generasi muda khususnya generasi Y (Gen Y) di Indonesia saat ini telah mengenal dan melakukan pembelian barang dan jasa secara daring (online). Hal ini tak lepas dari kemampuan situs belanja daring untuk menarik konsumen melalui berbagai promosi dan iklannya yang menjanjikan berbagai kelebihan belanja daring dibanding belanja secara konvensional, sehingga mampu menggugah emosi konsumen. Penelitian ini bertujuan untuk menguji faktor emosi $\left(\mathrm{X}_{1}\right)$ dan kepercayaan $\left(\mathrm{X}^{2}\right)$ terhadap orientasi belanja daring $(\mathrm{Y})$. Populasi dalam penelitian ini adalah anak muda di kota Batam belanja daring dan sampel dalam penelitian ini sebanyak 246 responden yang diambil secara acak (random sampling). Pengujian dilakukan menggunakan metode Structural Equation Modelling (SEM) dengan teknik Generalize Least Square (GLS). Hasil dari penelitian ini menunjukkan bahwa emosi dan kepercayaan terbukti sangat berpengaruh terhadap orientasi belanja daring khususnya bagi konsumen dikalangan muda.
\end{abstract}

Kata Kunci: emosi, kepercayaan, orientasi belanja daring, SEM, GLS

\begin{abstract}
Almost all young people, especially students in Indonesia, now know and purchase goods and services online. This is inseparable from the ability of online shopping sites to attract consumers through various promotions and advertisements that promise various advantages of online shopping compared to conventional shopping, so as to arouse consumer emotions. This study aims to examine emotional factors $(X 1)$ and trust $(X 2)$ towards online shopping orientation (Y). The population in this study were online shopping consumers in Batam city, and the samples in this study were 246 respondents who were taken randomly. Tests are carried out using the Structural Equation Modeling (SEM) method with the Generalize Least Square (GLS) technique. The results of this study indicate that emotions and trust proved to be very influential on the orientation of online shopping especially for consumers among young people.

Keywords: emotions, trust, online shopping orientation, SEM, GLS
\end{abstract}

\section{A. PENDAhULUAN}

Hinggga kini, para pemasar sudah umum menggunakan insentif moneter untuk meningkatkan peluang rekomendasi, sehingga memberikan motivasi eksternal bagi pembeli (Reimer \& Benkenstein, 2018). Perubahan dalam hal bagaimana, ketika, dan di mana dibalik motif komunikasi pemasaran bentuk customer-to-business dan customer-to-customer terbentuk bersamaan dengan diusulkannya bentuk definisi baru tentang WOM (word-ofmouth) dan UGC (user generated content) yang muncul di pasar (Naylor, 2016). Orientasi belanja seseorang terhadap suatu situs belanja dalam jaringan (daring/online) bisa seketika berubah jika diketahui terdapat persepsi tidak baik pada perusahaan. Seseorang membeli barang yang hanya berdasarkan insentif moneter atau yang lebih dikenal dengan promo memberikan rasa kecurigaan terhadap kualitas barang atau malah terhadap perusahaan yang menjual. Ini sangat mungkin mempengaruhi kepercayaan calon pembeli.

Motif lain seseorang memberi rekomendasi agar membeli secara daring adalah kepuasan konsumen dengan produk atau jasa, sehingga memberikan imbalan kepada perusahaan berupa keinginan membantu untuk merekomendasikan kepada orang lain (Sundaram, Mitra, \& Webster, 1998). Keadaan ini juga bisa menjadi faktor emosi yang 
mendorong seseorang untuk kembali membeli secara daring pada situs belanja yang sudah memberinya kepuasan. Seiring dengan itu maka orientasi seseorang akan dapat diarahkan dalam melakukan belanja sesuai rekomendasi orang yang sudah pernah terpuaskan oleh situs tertentu tanpa berpikir bahwa kejadiannya bisa sangat berbeda jika yang membeli berbeda orang atau berbeda kepentingan.

Konsumen muda atau remaja adalah pasar potensial untuk belanja daring. Hal ini karena segmen muda paling sensitif terhadap perkembangan teknologi yang menyentuh setiap aktivitasnya, termasuk dalam hal pembelian barang dan jasa. Hal ini karena secara psikologis, remaja adalah masa peralihan dari masa anak dengan masa dewasa yang mengalami perkembangan semua aspek/ fungsi untuk memasuki masa dewasa (Rumini, S., $\&$ Sundari, S. (2004). Pada masa ini, remaja paling mudah untuk disentuh dan diarahkan emosinya untuk melakukan sesuatu termasuk belanja secara daring.

Berdasarkan latar belakang yang telah disampaikan penulis bermaksud menguji apakah faktor emosi dan faktor kepercayaan cukup untuk mendorong orang memiliki orientasi belanja terhadap suatu situs belanja daring tertentu.

\section{B. TINJAUAN PUSTAKA}

\section{Pemanfaatan Internet di Kota Batam}

Kota Batam adalah sebuah kota terbesar di Propinsi Kepulauan Riau, Indonesia. Wilayah Kota Batam terdiri dari Pulau Batam, Pulau Rempang dan Pulau Galang dan pulaupulau kecil lainnya di kawasan Selat Singapura dan Selat Malaka. Batam merupakan salah satu kota dengan letak yang sangat strategis. Selain berada di jalur pelayaran internasional, kota ini memiliki jarak yang sangat dekat dan berbatasan langsung dengan Singapura dan Malaysia. Sebagai kota terencana, Batam merupakan salah satu kota dengan pertumbuhan terpesat di Indonesia. Hal ini juga membuat gaya hidup masyarakatnya menjadi peniru pertama budaya yang ada di negara tetangganya yang lebih cepat maju perekonomiannya. Gaya modern masyarakat Batam tidak lepas dari penggunaan telepon seluler yang menjadi sangat diminati untuk mengakses internet. Pemakaian dan pengaksesan internet membawa keuntungan yang banyak kepada pemakai internet seperti produktivitas pekerjaan, pendidikan, pengaksesan informasi, memperbaharui teknologi, persatuan sosial dan profesional, serta keuntungan bagi pembeli (Harris \& Fitriansyah, 2018).

Perkembangan Usaha Kecil dan Menengah (UKM) di kota Batam juga menunjukkan angka yang signifikan (Putra, 2014). Pemerintah kota Batam menyadari bahwa apabila dibina dan diperhatikan, UKM di Batam akan dapat berperan maksimal. Karena itu, pemerintah setempat menerbitkan Peraturan Daerah (Perda) Kota Batam Nomor 4 Tahun 2015 tentang Pembangunan Daerah Berbasis Daya Saing Melalui Inovasi dan Kompetensi, inisiatif untuk meningkatkan daya saing UKM dengan berbagai program perlu dilakukan. Selain melakukan sertifikasi produk, hal lain yang dapat dilakukan untuk meningkatkan daya saing adalah dengan optimalisasi pemanfaatan Teknologi Informasi (TI). Pemanfaatan teknologi telah terbukti mampu meningkatkan kinerja organisasi termasuk UKM (Mutiarni, $\mathrm{R}, 2017$ )

Perkembangan UKM yang sangat baik tersebut, juga direspon baik oleh para konsumen, khususnya generasi muda. Berbagai produk barang dan jasa yang dihasilkan pelaku UKM di Batam, ternyata mampu menarik minat konsumen khususnya anak muda untuk membeli. Hanya dengan berbekal telepon pintar dan jaringan internet yang handal, bisnis yang mulanya hanya dipasarkan secara konvensional, saat ini mampu dipasarkan dan dijual secara daring, sehingga makin meningkatkan perekonomian di Batam. 


\section{Penggolongan Usia Remaja Dan Dewasa}

Remaja berasal dari kata latin adolensence yang berarti tumbuh atau tumbuh menjadi dewasa. Dalam arti yang lebih luas lagi dewasa ini mencakup kematangan mental, emosional sosial dan fisik (Hurlock, 1992). Pasa masa ini sebenarnya tidak mempunyai tempat yang jelas karena tidak termasuk golongan anak tetapi tidak juga golongan dewasa atau tua (Deswita, 2006: 192)

Penggolongan remaja yang umum digunakan oleh para ahli adalah antara 12 hingga

21 tahun. Rentang waktu usia remaja ini terbagi atas 3 (tiga) yaitu

1. $12-15$ tahun adalah masa remaja awal

2. 15 - 18 tahun adalah masa remaja pertengahan

3. $18-21$ tahun adalah masa remaja akhir.

Monks, Knoers, dan Haditono (2002) membedakan masa remaja menjadi empat bagian yaitu

1. Masa pra-remaja $10-12$ tahun

2. Masa remaja awal $12-15$ tahun

3. Masa remaja pertengahan $15-18$ tahun

4. Masa remaja akhir $18-21$ tahun

Diatas kategori umur diatas, sudah termasuk dalam kategori usia dewasa. Secara umum usia dewasa adalah antara 20-40 tahun (Hurlock, E. B. 2001). Saat ini, muncul istilah anak muda yang disebut generasi Y (Gen Y). Secara umum, gen Y adalah generasi yang tumbuh di tengah-tengah perkembangan teknologi nirkabel, akrab dengan internet dan aktif di media sosial dan cenderung suka unjuk diri. Hal ini ikut memengaruhi kepekaan gen Y terhadap perubahan, yang dicirikan dengan tidak takut perubahan namun sering kali tak sabar melalui proses menuju perubahan itu. Namun demikian, generasi ini memiliki sikap kreativitas tanpa batas dan menyukai lingkungan kerja yang santai penuh hura-hura yang menampung kreativitas mereka. Mereka bekerja tidak terlalu serius, karena bekerja bukan untuk kehidupan atau menghidupi keluarga seperti yang dilakukan generasi sebelumnya. Generasi ini sangat techno-minded dan berinteraksi lebih banyak melalui gadget (Skype, Whatsapp, Twitter, Facebook) meskipun dengan lingkungan yang sangat dekat (Mucharom, L, dalam Suryadi, B, 2015)

\section{Hubungan Emosi dan Kepercayaan}

Pendekatan secara psikologis pada konsumen dilakukan agar mempelajari lebih fokus mengenai faktor budaya, demografik, motivasi, dan orientasi belanja seseorang (Dennis, Merrilees, Jayawardhena, \& Wright, 2009; Zhou, Dai, \& Zhang, 2007). Sehingga untuk mencari tahu faktor yang paling sederhana dalam menerka kebiasaan konsumen dalam membeli secara daring, penelitian ini harus mempelajari paling tidak 4 faktor tersebut di atas. Namun menurut Vajjhala \& Strang, (2018) kebahagiaan konsumen dan kepuasan konsumen memiliki hubungan yang sangat kuat terhadap keinginan membeli melalui internet. Kemudian membantu orang lain, menyakiti orang lain, membantu diri sendiri sambil membantu orang lain, semua itu memberikan motif palsu atau motif yang dibesar-besarkan UGC (user generated content) (Naylor, 2016). Ini membuat kepercayaan menjadi satu faktor yang dapat dibentuk untuk mempengaruhi kepercayaan seseorang terhadap situs daring digital. Sehingga dikatakan juga oleh Naylor, (2016) bahwa konsumen sangat mempercayai nilai numerik yang diberikan pada rating yang bisa saja diberikan oleh reviewer yang dibayar, kecuali apabila konsumen tersebut memang membaca feedback yang ada. Dengan 
sangat meyakinkan, telah ditunjukkan bahwa perilaku para pembeli daring secara kompleks dipengaruhi oleh nilai-nilai internal pembelanjaan dan juga isyarat-isyarat eksternal dari atmosphere yang diberikan oleh situs daring (Prashar, Vijay, \& Parsad, 2017). Menonjolkan rancangan yang dapat menjawab kebutuhan hedonis dan fungsionalitas yang tanpa cela merupakan hal penting dalam usaha mendapatkan loyalitas dari pelanggan Gen Y (Bilgihan, 2016). Hedonis merupakan salah satu penyusun faktor emosi.

Dari latar belakang serta tinjauan pustaka yang telah disampaikan maka hipotesis yang diangkat pada penelitian ini adalah:

$\mathrm{H}_{1}$ : Emosi konsumen mempengaruhi orientasi belanja pada situs belanja daring.

$\mathrm{H}_{2}$ : Kepercayaan konsumen mempengaruhi orientasi belanja pada situs belanja daring.

\section{METODE PENELITIAN}

Penelitian ini berjenis explanatory research dengan pendekatan kuantitative. Populasi dalam penelitian ini adalah remaja di kota Batam yang pernah melakukan pembelian daring menggunakan media internet, aplikasi, maupun situs web. Sampel yang diambil dalam penelitian ini sejumlah 246 responden. Pengambilan sampel menggunakan metode purposive sampling, yaitu metode pemilihan sampel secara tidak acak, dimana informasi menggunakan pertimbangan tertentu (Indriantoro \& Supomo, 2002). Horison waktu yang digunakan adalah studi cross sectional. Studi cross sectional merupakan studi untuk mengetahui hubungan komparatif beberapa subyek yang diteliti. (Indriantoro \& Supomo, 2002).

Data yang digunakan adalah data primer yang bersumber langsung dari responden, yang diperoleh melalui kuisioner. Selanjutnya , dari data yang masuk diolah dengan menggunakan aplikasi program Structural Equation Modelling (SEM). Model persamaan struktural, SEM adalah sekumpulan teknik-teknik statistikal yang memungkinkan pengujian sebuah rangkaian hubungan yang relatif "rumit", secara simultan. Kesesuaian model dievaluasi melalui telaah terhadap berbagai kriteria model fit Index. Teknik yang digunakan adalah Generalize Least Square (GLS).

\section{HASIL DAN PEMBAHASAN}

\section{Statistik Deskriptif}

Responden yang didapat adalah 296 orang yang kemudian dilakukan pemilahan terhadap isian yang tidak lengkap dan tidak jelas. 246 data yang lengkap digunakan sebagai sampel penelitian yang memiliki deskripsi sebagai berikut:

Tabel 1: Deskripsi Responden

\begin{tabular}{lc}
\hline \multicolumn{1}{c}{ Keterangan } & Jumlah \\
\hline Jenis Kelamin & \\
a. Laki-laki & 101 orang \\
b. Perempuan & 145 orang \\
\hline & \\
Usia & Tidak ada \\
a. $10-15$ tahun & 182 orang \\
b. $16-21$ tahun & 48 orang \\
c. $22-27$ tahun & 10 orang \\
b. $28-33$ tahun & 6 orang \\
d. 33 tahun atau lebih & \\
\hline
\end{tabular}




\begin{tabular}{lc}
\hline Tempat belanja & 33 orang \\
a. Tokopedia & 18 orang \\
b. Lazada & 2 orang \\
c. Blanja.com & 165 orang \\
d. Shopee & 5 orang \\
e. Bukalapak & 23 orang \\
f. Lainnya & \\
\hline Penghasilan / bulan & $\geq 1$ jt rupiah sampai dengan \\
\hline Sumber rupiah
\end{tabular}

Sumber: Data Primer diolah, 2018

Tabel 2: Deskripsi Statistik

\begin{tabular}{ccccc}
\hline & Jumlah & Minimum & Maksimum & Rerata \\
\hline Faktor Emosi & 246 & 2 & 4 & 2,41 \\
\hline Faktor Kepercayaan & 246 & 2 & 4 & 2,99 \\
\hline Orientasi Belanja & 246 & 1 & 4 & 2,79 \\
\hline
\end{tabular}

Sumber: Data primer diolah, 2018

Berdasarkan tabel Deskripsi Statistik dapat diambil pemahaman bahwa dari seluruh responden telah menyatakan setuju secara rerata terhadap semua pertanyaan responden yang diberikan.

Selanjutnya, dari data primer yang masuk dilakukan uji ketepatan model. Model penelitian menggunakan 2 variabel tidak terikat, yaitu: Faktor Emosi (E) dan Faktor Kepercayaan $(\mathrm{T})$ terhadap variabel terikat Orientasi Belanja (PO).

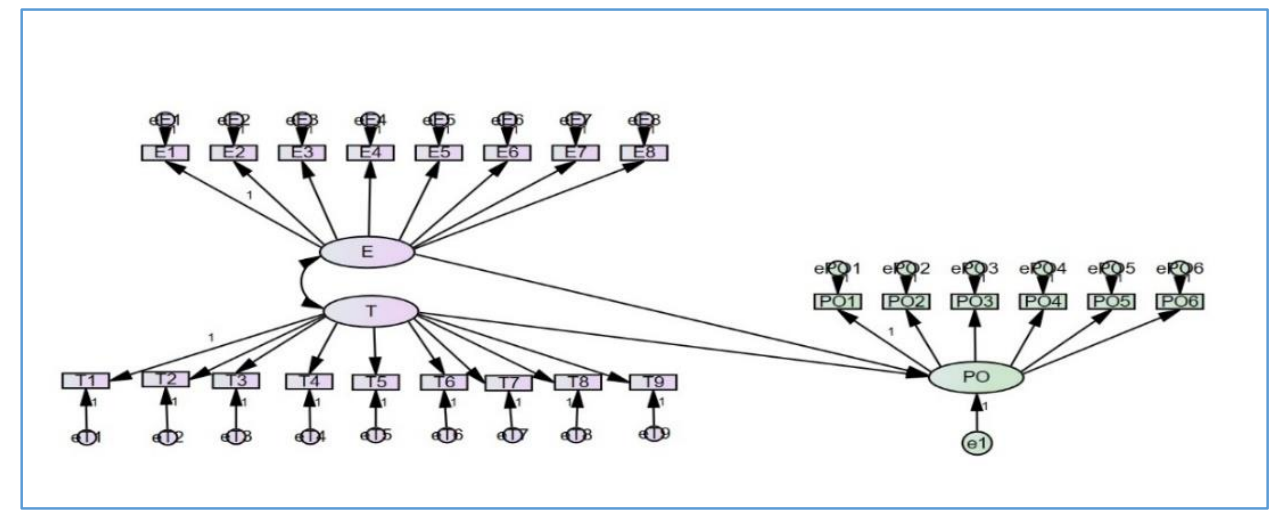

Gambar 1: Model Penelitian

Untuk memastikan penggunaan model penelitian yang tepat, uji model of fitness dilakukan menggunakan IBM $^{\circledR}$ SPSS $^{\circledR}$ AMOS berdasarkan asumsi CMIN/DF (the minimum sample discrepancy function/degree of freedom) $\leq 2$. Uji ini menghitung chisquare dibagi dengan degree of freedom. Teknik yang digunakan adalah Generalize Least Square (GLS).

Tabel 3: Model Fit Summary

\begin{tabular}{|l|rrrrr|}
\hline Model & NPAR & CMIN & DF & P & CMIN/DF \\
\hline Emosi dan Kepercayaan thdp Orientasi Belanja & 49 & 430,536 & 227 &, 000 & 1,897 \\
Saturated model & 276 &, 000 & 0 & & \\
Independence model & 23 & 650,923 & 253 &, 000 & 2,573 \\
Zero model & 0 & 2817,500 & 276 &, 000 & 10,208 \\
\hline
\end{tabular}

Sumber: Data primer diolah, 2018 
Selanjutnya, untuk menganalisis hipotesis yang diajukan, peneliti menguji 3 (tiga) variabel yang dinilai berdasarkan indikator yang diberikan pada setiap variabel yang digunakan. Berikut rincian dari indikator yang digunakan:

\section{Tabel 4: Indikator Pertanyaan}

\begin{tabular}{|c|c|}
\hline \multicolumn{2}{|r|}{ Faktor Emosi } \\
\hline No. & Indikator Pernyataan \\
\hline 1 & Saya merasa tenang jika sedang melakukan belanja online \\
\hline 2 & $\begin{array}{l}\text { Saya selalu memiliki harapan yang terbaik jika sedang melakukan belanja } \\
\text { online }\end{array}$ \\
\hline 3 & Saya merasa penuh semangat jika sedang melakukan belanja online \\
\hline 4 & Saya merasa bangga jika melakukan belanja online \\
\hline 5 & Saya merasa frustasi jika melakukan belanja online \\
\hline 6 & Saya merasa khawatir dalam melakukan belanja online \\
\hline 7 & Saya merasa tertekan jika sedang melakukan belanja online \\
\hline 8 & Saya merasa dipermalukan jika melakukan belanja online \\
\hline \multicolumn{2}{|r|}{$\begin{array}{l}\text { Faktor Kepercayaan } \\
\end{array}$} \\
\hline No. & Indikator Pernyataan \\
\hline 1 & $\begin{array}{l}\text { Situs perbelanjaan online yang biasa saya gunakan adalah situs yang terpercaya } \\
\text { dan jujur }\end{array}$ \\
\hline 2 & $\begin{array}{l}\text { Situs perbelanjaan online yang biasa saya gunakan adalah situs yang menepati } \\
\text { janji dan kewajibannya }\end{array}$ \\
\hline 3 & $\begin{array}{l}\text { Informasi yang diberikan oleh situs perbelanjaan online yang biasa saya } \\
\text { gunakan sangat banyak dan memadai }\end{array}$ \\
\hline 4 & $\begin{array}{l}\text { Infrastruktur dari situs perbelanjaan online yang saya gunakan dapat } \\
\text { diandalkan }\end{array}$ \\
\hline 5 & $\begin{array}{l}\text { Situs perbelanjaan online yang biasa saya gunakan menawarkan pengamanan } \\
\text { privasi pribadi }\end{array}$ \\
\hline 6 & $\begin{array}{l}\text { Menurut saya situs perbelanjaan online yang biasa saya gunakan terus menjadi } \\
\text { situs online yang terbaik }\end{array}$ \\
\hline 7 & $\begin{array}{l}\text { Dibandingkan dengan situs perbelanjaan online lain, situs perbelanjaan online } \\
\text { yang biasa saya gunakan aman dapat diandalkan }\end{array}$ \\
\hline 8 & $\begin{array}{l}\text { Situs perbelanjaan online yang saya gunakan tidak akan berperilaku opurtunis } \\
\text { (misalnya, mendapatkan keuntungan secara 86lterna) }\end{array}$ \\
\hline 9 & Situs perbelanjaan online yang biasa saya gunakan memenuhi harapan saya \\
\hline \multicolumn{2}{|r|}{ Orientasi Belanja Online } \\
\hline No. & $\begin{array}{l}\text { Indikator Pernyataan } \\
\end{array}$ \\
\hline 1 & Saya lebih suka membeli produk/jasa melalui situs perbelanjaan online \\
\hline 2 & Penting bagi saya untuk membeli produk/jasa secara online \\
\hline 3 & $\begin{array}{l}\text { Sering kali saya menemukan produk/jasa yang saya butuhkan di situs } \\
\text { perbelanjaan online }\end{array}$ \\
\hline 4 & $\begin{array}{l}\text { Tersedianya produk/jasa yang berkualitas tinggi yang ditawarkan oleh situs } \\
\text { perbelajaan online sangat penting bagi saya }\end{array}$ \\
\hline 5 & Saya menemukan kualitas produk/jasa yang lebih baik ketika berbelanja online \\
\hline 6 & $\begin{array}{l}\text { Saya mempunyai standar dan harapan yang tinggi terhadap produk/jasa yang } \\
\text { saya beli secara online }\end{array}$ \\
\hline
\end{tabular}

Dalam SEM (structural equation modelling) ukuran sampel menjadi salah satu faktor yang penting. Ukuran sampel dalam metode-metode penelitian lainnya menjadi dasar untuk mengestimasi kesalahan sampling. Dengan jumlah responden antara 200-500 orang, maka pada penelitian ini digunakan teknik GLS. Uji model menghasil kesimpulan bahwa faktor Emosi dan Faktor Kepercayaan secara bersamaan dapat mempengaruhi Orientasi Belanja daring seseorang sebesar $62 \%$. Berikut adalah rancangan uji model yang digunakan: 


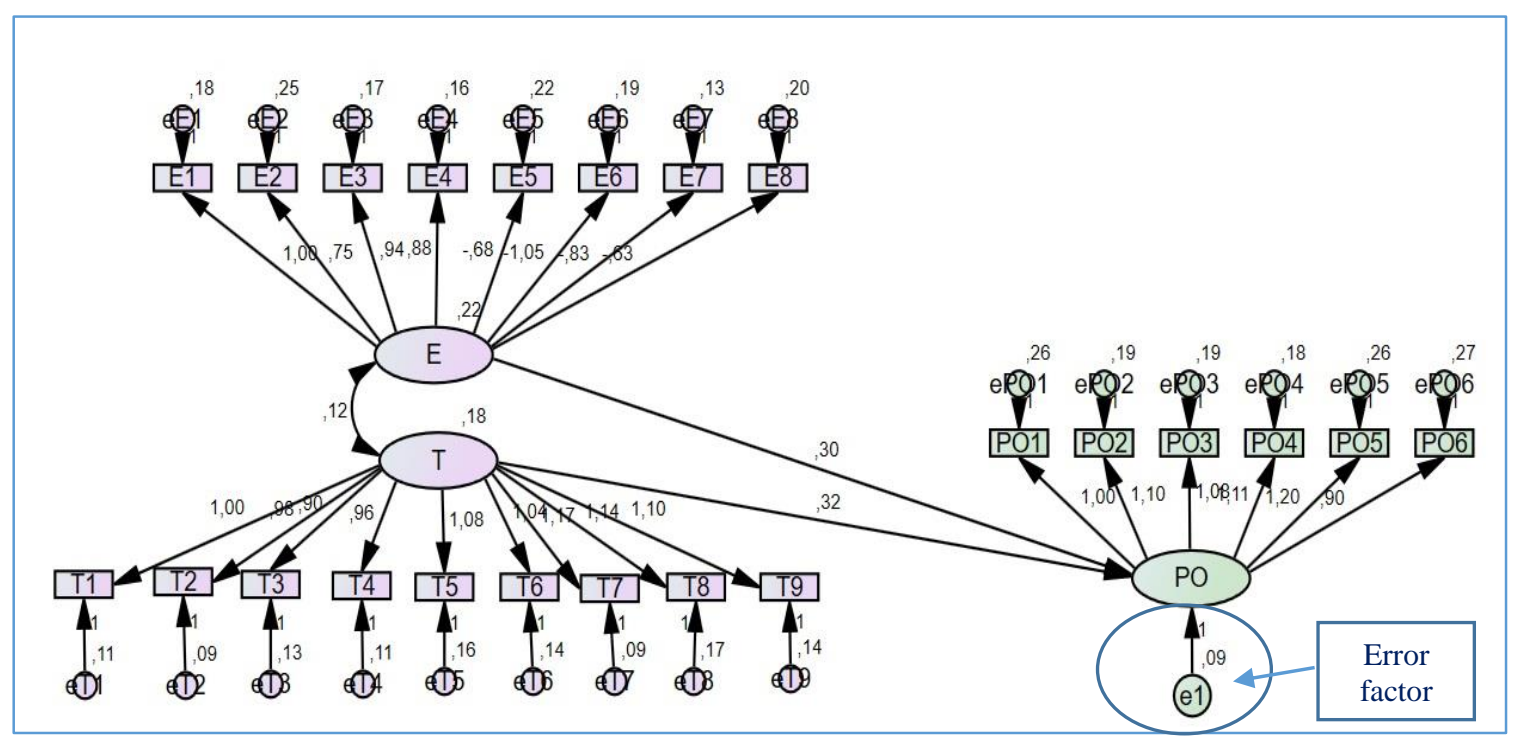

Gambar 2: Hasil uji Model

Masing-masing faktor Emosi mempengaruhi sebesar 30\% dan faktor Kepercayaaan sebesar 32\%, sisanya dipengaruhi oleh faktor lain yang tidak diteliti dengan faktor kesalahan sebesar $9 \%$. Hipotesis alternatif yang diusulkan dalam penelitian ini semuanya dapat diterima

\section{E. PENUTUP}

Dari hasil penbelitian diatas dapat disimpulkan bahwa faktor emosi dan faktor kepercayaan seseorang cukup untuk memprediksikan Orientasi Belanja seseorang secara daring (online). Ini ditunjukkan dengan nilai persen sebesar $62 \%$ yang dihasilkan oleh uji SEM. Dengan hasil ini diusulkan bagi pengelola pasar daring (online marketplace) agar bisa lebih fokus untuk mengelola dan menjaga kedua faktor tersebut lebih baik lagi dibandingkan faktor lainnya yang hanya punya konstribusi $38 \%$. Model yang rancang juga memiliki fitness yang baik dalam memprediksi orientasi belanja yang diinginkan sehingga bisa diasumsikan bahwa hubungan 3 variabel di atas mampu memberikan generalisasi.

Kontribusi dari penelitian ini adalah menjelaskan bahwa emosi dan kepercayaan sangatlah penting untuk diperhatikan jika ingin mendapatkan pelanggan muda. Melihat jumlah responden yang mayoritas berusia 16-21 tahun ini mengkategorikan pelanggan dari kalangan Gen Y. Berdasarkan peneltian yang dilakukan di India oleh Bilgihan, (2016) website yang terpercaya akan lebih banyak dikunjungi dan akan membangkitkan tingkat loyalitas pelanggan dari golongan Gen Y. Sehingga membangun website yang menarik secara kaidah keindahan dapat memberikan motivasi Gen Y menjadi loyal dalam konteks daring. Loyalitas biasanya dicerminkan dengan kemauan dalam membeli secara berulang pada pasar daring yang sama.

\section{DAFTAR PUSTAKA}

Bilgihan, A. (2016). Gen Y Customer Loyality in Online Shopping: An Integrated Model of Trust, User Experience and Branding. Computers in Human Behavior, 61, 103113. 
Dennis, C., Merrilees, B., Jayawardhena, C., \& Wright, L. T. (2009). E-Consumer Behavior. European Journal of Marketing, 42(9), 1121-1139.

Harris, I., \& Fitriansyah, A. (2018). Pengaruh Efektivitas Diri Dan Spesifik Internet Terhadap Tingkat Ansietas Pengguna Internet. JMD: Jurnal Riset Manajemen \& Bisnis Dewantara, 1(2), 97-108.

Hurlock, E. B. (2001). Developmental psychology. Tata McGraw-Hill Education Indriantoro, N., \& Supomo, B. (2002). Metodologi Penelitian Bisnis untuk Akuntansi dan Manajemen. Yogyakarta: BPFE-Yogyakarta.

Monks, F. J., \& Knoers, A. M. P. Siti Rahayu Haditono. 2002. Psikologi Perkembangan; Pengantar dalam berbagai bagiannya.

Mutiarni, R. (2017). Implementasi Electronic Data Processing Pada Koperasi Wanita. Eksis. Jurnal Riset Ekonomi dan Bisnis, 12(2), 135-148.

Naylor, G. S. (2016). Complaining Complimenting And Word-Of-Mouth in The Digital Age: Typology and Terms. https://www.researchgate.net/publication/313036749 (ss. 131-142). ResearchGate.

Prashar, S., Vijay, T. S., \& Parsad, C. (2017). Effect of Online Shopping Values and Website Cues on Purchase Behaviour: A Study Using S-O-R Framework. The Journal of Decision Makers, 42(1), 1-18.

Reimer, T., \& Benkenstein, M. (2018). Not just for the recommender: How eWOM incentives influence the recommendation audience. Journal of Business Research, 86(January), 11-21. doi:10.1016/j.jbusres.2018.01.041

Rumini, S., \& Sundari, S. (2004). Perkembangan anak dan remaja. Jakarta: Rineka Cipta.

Sundaram, D. S., Mitra, K., \& Webster, C. (1998). Word-Of-Mouth Communications: a Motivational Analysis. NA - Advances in Consumer Research, 25, 527-531.

Suryadi, B. (2015, May). Generasi y: karakteristik, masalah, dan peran konselor. Seminar dan Workshop Internasional MALINDO 4 di Bali, 22-23 Mei 2015. Diselenggarakan oleh Asosiasi Bimbingan dan Konseling Indonesia (ABKIN)Vajjhala, N. R., \& Strang, D. K. (2018). Examining Internet Behavior of young Technology-Literate Consumers in India. Twenty-fourth Americas Conference on Information Systems. New Orleans.

Wu, W.-Y., Ke, C.-C., \& Nguyen, P.-T. (2018). Online Shopping Behavior in Electronic Commerce: An Integrative Model form Utilitarian and Hedonic Perspectives. International Journal of Entrepreneurship, 22(3).

Zhou, L., Dai, L., \& Zhang, D. (2007). Online Shopping Acceptance Model - A Critical Survey of Consumer Factors in Online Shopping. Journal of Electronic Commerce Research, 8(1), 41-62. 